\title{
Effects of Sodium Oxybate on Sleep Physiology and Sleep/Wake-related Symptoms in Patients with Fibromyalgia Syndrome: A Double-blind, Randomized, Placebo-controlled Study
}

\author{
HARVEY MOLDOFSKY, NEIL H. INHABER, DIANE R. GUINTA, and SARAH B. ALVAREZ-HORINE
}

ABSTRACT. Objective. To determine the effects of sodium oxybate (SXB) on sleep physiology and sleep/ wake-related symptoms in patients with fibromyalgia syndrome (FM).

Methods. Of 304 patients with FM (American College of Rheumatology tender point criteria) in the screened study population, 209 underwent polysomnography, 195 were randomized, and 151 completed this 8-week, double-blind, placebo-controlled study of SXB $4.5 \mathrm{~g}$ and $6 \mathrm{~g} / \mathrm{night}$. We evaluated changes in objective sleep measures and subjective symptoms, including daytime sleepiness [Epworth Sleepiness Scale (ESS)], fatigue visual analog scale (FVAS), sleep [Jenkins Scale for Sleep (JSS)], and daytime functioning [Functional Outcome of Sleep Questionnaire (FOSQ), SF-36 Vitality domain, and Fibromyalgia Impact Questionnaire (FIQ) general and morning tiredness].

Results. Pretreatment screening revealed an elevated incidence of maximum alpha EEG-intrusion > $24 \mathrm{~min} /$ hour of sleep $(66 \%)$, periodic limb movements of sleep $(20.1 \% \geq 5 /$ hour $)$, and moderate to severe obstructive sleep apnea disorder (15.3\% apnea-hypopnea index $\geq 15 /$ hour). Compared with placebo, both doses of SXB achieved statistically significant improvements in ESS, morning FVAS, JSS, FOSQ, SF-36 Vitality, and FIQ general and morning tiredness; both doses also demonstrated decreased rapid eye movement (REM) sleep (all p $\leq 0.040$ ). SXB 6 g/night improved afternoon, evening and overall FVAS, reduced wakefulness after sleep onset, and increased Stage 2, slow-wave, and total non-REM sleep (all $\mathrm{p} \leq 0.032$ ) versus placebo. Moderate correlations $(\geq 0.40)$ were noted between changes in subjective sleep and pain measures. Adverse events occurring significantly more frequently with SXB than placebo were nausea, pain in extremity, nervous system disorders, dizziness, restlessness, and renal/urinary disorders (including urinary incontinence).

Conclusion. This large cohort of patients with FM demonstrated that SXB treatment improved EEG sleep physiology and sleep-related FM symptoms. (First Release August 1 2010; J Rheumatol 2010;37:2156-66; doi:10.3899/jrheum.091041)

Clinical trial registry: ClinicalTrials.gov; clinical trial registration number NCT000875555.

Key Indexing Terms:

SODIUM OXYBATE

FIBROMYALGIA

POLYSOMNOGRAPHY

FATIGUE

According to the American College of Rheumatology (ACR) criteria for fibromyalgia (FM), the key criteria for diagnosing the disorder are widespread musculoskeletal pain and multiple tender points in specific anatomical sites $^{1}$. Although fatigue and sleep disturbances were not considered to be significant in differentiating patients with
FM from those with articular and connective tissue disease, subsequent clinical studies determined that the most commonly rated symptoms in over 2500 patients with FM in the US were unrefreshing sleep, morning stiffness, fatigue, pain, and problems with concentration and memory ${ }^{2}$. Similarly, a German survey of almost 700 patients with FM
From the Centre for Sleep and Chronobiology and the Toronto Psychiatric Research Foundation, Toronto, Ontario, Canada; and Jazz.

Pharmaceuticals, Inc., Palo Alto, California, USA.

Supported by Jazz Pharmaceuticals, Inc. Palo Alto, California, USA. Dr. Moldofsky has received research support from Eli Lilly, Krele, Pfizer,

Pierre Fabre, Sanofi Aventis, and Schering Plough; acts as a consultant for Boehringer Ingleheim, Eli Lilly, Jazz Pharmaceuticals, Krele, Lundbeck, Merck, Paladin Labs, Pfizer, Pierre Fabre, Sanofi Aventis, Schering Plough, and Valeant; and is on the speaker's bureau for Pfizer. Dr. Inhaber is a former employee of Jazz. Pharmaceuticals, Inc., and owns stock in the company. S.B. Alvarez-Horine and D.R. Guinta are employees of Jazz Pharmaceuticals, Inc., and own stock and stock options in the company. Editorial review and manuscript preparation were by Susanna Grzeschik, PhD, RPh, and Daniel Pardi, MS, former employees of Jazz
Pharmaceuticals, Inc., and by Deborah Waxman, MA, as well as statistical support from Efim A. Dynin, PhD, and Chinglin Lai, PhD, all from Jazz Pharmaceuticals, Inc.

H. Moldofsky, MD, FRCPC, Centre for Sleep and Chronobiology and the Toronto Psychiatric Research Foundation; N.H. Inhaber, MD, FRCPC, Respiratory Medicine, Novartis Pharmaceuticals, East Hanover, NJ; D.R. Guinta, PhD, Clinical Development and Scientific Affairs; S.B. Alvarez-Horine, MS, Biostatistics, Jazz Pharmaceuticals, Inc. Address correspondence to Dr. H. Moldofsky, Centre for Sleep and Chronobiology, 340 College Street, Suite 580, Toronto, Ontario M5T 3A9. E-mail: h.moldofsky@utoronto.ca.

Full Release Article. For details see Reprints/Permissions at jrheum.org. Accepted for publication May 20, 2010.

Personal non-commercial use only. The Journal of Rheumatology Copyright (c) 2010. All rights reserved 
showed that the most common symptoms were chronic widespread pain, unrefreshing sleep, and subjective disabilities $^{3}$. In a one-year prospective US study of almost 500 patients with FM, $94.7 \%$ reported persistent poor sleep quality ${ }^{4}$. Sleep and fatigue are also among the principal domains identified by the clinician-investigators, patients, and the OMERACT (Outcome Measures in Rheumatoid Arthritis Trials) group and are recommended key domains to be studied in trials in FM, a multisymptom syndrome ${ }^{5}$.

Prospective clinical studies have demonstrated a correlation between poor sleep quality and FM symptoms. The statistical path analysis by Bigatti, et $a l^{4}$ showed that a night of greater sleep disturbances predicted greater pain. This predicted poorer physical functioning, which in turn predicted greater depression ${ }^{4}$. That study extended the previous findings by Affleck, et al, who showed that a night of poorer sleep was followed by a more painful day with an across-person analysis but that the change in sleep quality was not explained by changes in pain intensity at the within-person level $^{6}$. A further study showed that after accounting for the effects of positive events, negative events, and pain on daily affect scores, sleep duration and quality were prospectively related to affect and fatigue. Inadequate sleep had a cumulative effect on negative affects and prevented affective recovery from days with a high number of negative events ${ }^{7}$.

In their attempts to determine the physiological basis of poor sleep quality, a number of investigators have performed polysomnographic (PSG) studies in patients with FM. Various alterations in non-rapid eye movement (non-REM) sleep physiology have been identified. These include the presence of a prominent alpha ( 7 to $12 \mathrm{~Hz}$ ) electroencephalographic (EEG) non-REM sleep anomaly, commonly called alpha intrusions or alpha EEG sleep disorder, which has been observed in most studies $8,9,10,11,12,13$. This anomaly acts as an indicator of a vigilant state during non-REM sleep, with resulting daytime symptoms of unrefreshing or nonrestorative sleep ${ }^{14}$. The anomaly was not reported in a recent small-scale study that focused on the presence of alpha EEG during a selected component of nonREM sleep, i.e., delta EEG sleep [or slow-wave sleep $(\mathrm{SWS})]^{15}$. Other reported alterations are a reduction in stage 2 sleep spindles ${ }^{16}$, shorter duration of stage 2 sleep peri$\operatorname{ods}^{17}$, and a high frequency of cyclical alternating pattern $(\mathrm{CAP})^{18}$. CAP is a periodic EEG sleep phenomenon that is an objective physiological measure of the stability of sleep. The CAP phase A1 pattern is an index of sleep stability, and CAP phase A2 and A 3 are indices of progressive sleep instability or poor quality of sleep. Increases in such activities are found in patients with FM, where their poor quality of sleep is associated with the severity of symptoms as measured by the number of tender points ${ }^{18}$. There are anecdotal reports of the presence of other periodic physiological disturbances, including restless legs syndrome and sleep apnea disorder, in $\mathrm{FM}^{9}$. Adding strength to this hypothesis are a variety of animal and human experimental studies that have demonstrated a causal connection between disturbances in normal sleep and measures of bodily pain 19,20,21,22,23,24,25,26,27. Older studies with tricyclic medications (cyclobenzaprine and amitriptyline) had no effect on the alpha EEG sleep anomaly or pain in $\mathrm{FM}^{28,29}$. Similarly, nonbenzodiazepine hypnotic drugs (zolpidem and zopiclone) improved sleep continuity but had no effect on altering SWS, the alpha EEG sleep anomaly, or the pain symptoms in subjects with $\mathrm{FM}^{30,31}$. Thus, it is reasonable to hypothesize that methods to improve sleep and modify sleep architecture might improve the body pain, fatigue, and mood in patients with FM.

Sodium oxybate (SXB), the sodium salt of gamma-hydroxybutyrate, which is a metabolite of the inhibitory neurotransmitter gamma-aminobutyric acid, can increase SWS and reduce sleep fragmentation in narcolepsy ${ }^{32}$. In investigating the role of disturbed sleep physiology in FM, Scharf, et al evaluated the efficacy of SXB in FM and showed that SXB increased SWS, reduced the alpha EEG sleep disorder, and improved pain and fatigue in a small group of patients ${ }^{33}$. To further assess the role of sleep physiology and symptomatology in FM, we measured the objective and subjective sleep characteristics of patients before and after 8 weeks of treatment with SXB.

\section{MATERIALS AND METHODS}

Our study was conducted in accord with the Declaration of Helsinki and received institutional review board approval applicable to each site. The sponsor monitored compliance according to good clinical practice (ICH E6) guidelines. The National Clinical Trials Identifier is NCT000875555.

Patients. Men or women 18 years of age or older who met the 1990 ACR classification criteria for $\mathrm{FM}^{1}$ were recruited and enrolled after providing informed consent.

Inclusion criteria required that the patient's average visual analog scale score for pain (PVAS) be $>4$ on a 0 to 10 point VAS, based on patient diary records for the week prior to randomization. In addition, patients agreed to adhere to the following rules during the study: discontinue opiates, antidepressants, cyclobenzaprine, and tramadol; continue with any preexisting nonpharmacologic regimen; restrict rescue analgesic therapies to the use of acetaminophen $\leq 4000 \mathrm{mg} /$ day, ibuprofen $\leq 1200 \mathrm{mg}$ /day, naproxen $\leq 660$ $\mathrm{mg}$ /day, or ketoprofen $\leq 75 \mathrm{mg}$ /day; forego ingestion of alcohol; and for women who were not surgically sterile or postmenopausal $\geq 2$ years, use a medically accepted method of birth control.

Patients were excluded if any of the following were found to apply: an inflammatory rheumatic disease; a painful disorder other than FM; hyperor hypothyroidism; a medical or psychological condition that might compromise participation in the study; an Apnea Hypopnea Index $>15$ per hour on a screening PSG (exempted if using satisfactory continuous positive airway pressure therapy that controlled the apneas/hypopneas); a seizure disorder; history of head trauma resulting in loss of consciousness; migraine headaches; intracranial surgery; current or recent history (within one year) of any substance abuse disorder (including alcohol); succinic semialdehyde dehydrogenase deficiency; taking SXB or any investigational therapy in the 30 days prior to the screening visit; any past use of anticonvulsants for epilepsy; unwillingness to stop use of anticonvulsants used for pain, any antidepressant (exempted if discontinued for at least 5 half-lives), sleep aids (such as hypnotics, tranquilizers, and antihistamines; nonsedating antihistamines were exempt), or benzodiazepines; serum creatinine $>2.0$ $\mathrm{mg} / \mathrm{dl}$; abnormal liver function tests (transaminase at least twice the upper limit of normal or serum bilirubin $\geq 1.5$ times the upper limit of normal); a

Personal non-commercial use only. The Journal of Rheumatology Copyright (C) 2010. All rights reserved. 
positive pregnancy test; an electrocardiogram that disclosed a clinically significant arrhythmia or an atrioventricular conduction delay greater than first-degree block; pending worker's compensation litigation or other monetary settlements; or an occupation that required night shift work.

Clinic sites. The study was conducted at 21 clinical sites in the continental US, with personnel experienced in diagnosing and caring for patients with FM. Collectively, the healthcare providers at these sites were identified as "the Oxybate SXB-26 FM Study Group" (see Acknowledgment).

Study design and treatment. The trial was an 8-week, randomized, double-blind, placebo-controlled study of SXB in the treatment of FM. After being screened for eligibility (Visit 1) and initiation of a washout period of up to 39 days (Visit 2), eligible subjects entered a 2-week baseline period in which they recorded their PVAS scores 3 times a day (Visit 3). At Visit 4 , those who had PVAS scores $\geq 4$ on a $0-10$ scale during the baseline period were randomized equally to one of 3 treatment groups: placebo, SXB $4.5 \mathrm{~g} / \mathrm{night}$, or SXB $6 \mathrm{~g} / \mathrm{night}$. All treatments were given nightly at bedtime and 2.5-4 hours later in 2 evenly divided doses. Treatment was 8 weeks in duration with 3 treatment visits: Visit 5 (2 weeks), Visit 6 (4 weeks), and Visit 7 (8 weeks).

At the end of the baseline period and prior to randomization at Visit 4, subjective sleep, fatigue, and daytime functioning were assessed using a series of questions eliciting sleep-related history, the Jenkins Scale for Sleep (JSS; a 4-item self-report questionnaire for sleep disturbance, including 3 questions on nighttime sleep and one on daytime tiredness, range 0-20: higher values indicate worse sleep) ${ }^{34}$, the Epworth Sleepiness Scale (ESS; an 8-item self-report questionnaire for daytime sleepiness assessing the likelihood of falling asleep during different daytime situations; range 0-24: higher values indicate more sleepiness) ${ }^{35}$, Fatigue VAS (FVAS; morning, afternoon, and evening daily diary; range 0-100: $0=$ no fatigue, $100=$ worst imaginable fatigue), and several measures of daytime functioning, including the Functional Outcome of Sleep Questionnaire (FOSQ; a series of questions evaluating the effects of daytime sleepiness on daily activities and function; range 5-20: lower values indicate worse functioning $)^{36}$, Short Form-36 Health Survey (SF-36) Vitality domain (evaluating the subjects' energy level; range 0-100: higher values indicate better function, normalized value for the US is 50$)^{37}$, and the Fibromyalgia Impact Questionnaire (FIQ) general and morning tiredness subscales (range 0-10: higher scores indicate more tiredness $)^{38}$. The JSS, ESS, FVAS, FOSQ, SF-36 Vitality domain, and FIQ general and morning tiredness were collected at timepoints throughout the study and at study end.

PSG was performed at the end of screening period (Visit 2), at the randomization visit, defined as baseline (Visit 4), and at Weeks 4 and 8 of treatment (Visits 6 and 7). PSG data were centrally scored using described methods ${ }^{39}$. PSG scorers were all certified PSG technologists and were required to have interrater reliability $>90 \%$. PSG measures included sleep onset latency (SOL), wake after sleep onset (WASO), and total sleep time, all of which were measured in minutes, as well as percentage sleep efficiency, number of EEG arousals, number of apneas/hypopneas and periodic limb movements per hour of sleep, and time spent in each sleep stage. Baseline alpha-intrusion was calculated as the percentage of time in alpha frequency during the first 4 hours of sleep, where the majority of time is spent in non-REM sleep. Patients received water at bedtime and 4 hours later during Visit 2 and Visit 4 PSG as a control for study drug administration during treatment. During Visit 6 and Visit 7 PSG, patients took study drug at bedtime and 4 hours later.

CAP was also assessed using a validated computerized automatic detection methodology (Somnologica ${ }^{40,41}$. The total CAP rate is the sum of CAP A1 and CAP A2/3. Subgroup analyses of CAP characteristics included measures of CAP phase A1 and CAP phases A2 and A3. For technical reasons, not all PSG machines allowed data conversion to European Data Format, which is required for the calculation of the CAP. Consequently, baseline CAP data were available for 88 of 195 randomized patients and for 47 of 151 patients who completed the study.

Other self-assessed outcome measures were used in the study, including the PVAS, FIQ, SF-36 Health Survey, and Patient Global Impression of
Change, and have been reported separately ${ }^{42}$. Clinician administered assessments included the tender point count and index, the clinician global impression of severity at baseline, and the clinical global impression of change at study end.

Tolerability and safety assessments. Safety and tolerability assessments for this study included spontaneously reported or observed treatment-emergent adverse events, 12-lead electrocardiographic measurements, clinical laboratory tests (hematology, chemistry, and urinalysis), vital sign measurements, and physical examination findings. Safety results from this study have been reported ${ }^{42}$ and are summarized here.

Statistical analysis. Randomization was achieved by computer-generated code using a block size of 6 . Outcome measures analyzed for this report include PSG data, FVAS, JSS, ESS, SF-36 Vitality, FOSQ, and FIQ (general and morning tiredness), which were secondary endpoints of the study protocol. No adjustments for multiplicity were made. For completeness, previously reported mean and median PVAS data are also included ${ }^{42}$. Baseline data were summarized for all randomized patients and for the population of patients who completed the study. Patients who completed the study were exposed to SXB or placebo for 8 weeks. Changes from baseline data were analyzed on the completed population, thereby avoiding imputation of data including the PSG data. To compare the treatment groups, analysis of variance was employed with treatment as the only factor. Mean change from baseline to study endpoint (Week 8) was reported. In the case of missing data, no imputation methods were applied. All statistical testing was 2-sided with a significance level of 5\%. SAS Version 9.1 for Windows (SAS, Cary, NC, USA) was used throughout. Correlations were analyzed between measures of change in PSG and change in subjective sleep and also between measures of change in subjective sleep and change in pain, using Spearman's correlation coefficient.

\section{RESULTS}

Figure 1 illustrates the progress of the study.

General characteristics of patients at baseline. Of 320 patients who were screened, 209 underwent PSG and 195 were randomized. Of 125 patients who failed screening, the most common reasons for failure were thyroid stimulating hormone test results being out of range (24), withdrawal of consent (18), sleep apnea or Apnea Hypopnea Index out of range (16), inability to discontinue current compromising drugs (12), did not meet PVAS criteria or ACR criteria for FM (12), lost to followup (7), and other pain disorders (6). No other screening failure reason included more than 4 subjects. Of note, in the population of $209 \mathrm{FM}$ patients screened using PSG, patients had an elevated incidence of maximum alpha EEG-intrusion $>24 \mathrm{~min} /$ hour of sleep (66\%), periodic limb movements of sleep $(20.1 \% \geq 5 /$ hour $)$, and moderate to severe obstructive sleep apnea disorder (15.3\%; Apnea-Hypopnea Index $\geq 15$ /hour).

Of the 192 treated patients, a higher percentage of patients completed the study in the placebo (82\%) and SXB $4.5 \mathrm{~g} / \mathrm{night}(82 \%)$ groups than in the SXB $6 \mathrm{~g} / \mathrm{night}$ group (69\%; Figure 1). More patients discontinued due to adverse events in the SXB $6 \mathrm{~g} /$ night group $(\mathrm{n}=14)$ than in the SXB $4.5 \mathrm{~g} / \mathrm{night}$ group $(\mathrm{n}=6)$ or the placebo group $(\mathrm{n}=3)$.

Demographic and baseline clinical characteristics were similar among the treatment groups for the randomized population. Baseline characteristics were also similar for the randomized patients and for the population that completed

Personal non-commercial use only. The Journal of Rheumatology Copyright (C) 2010. All rights reserved 


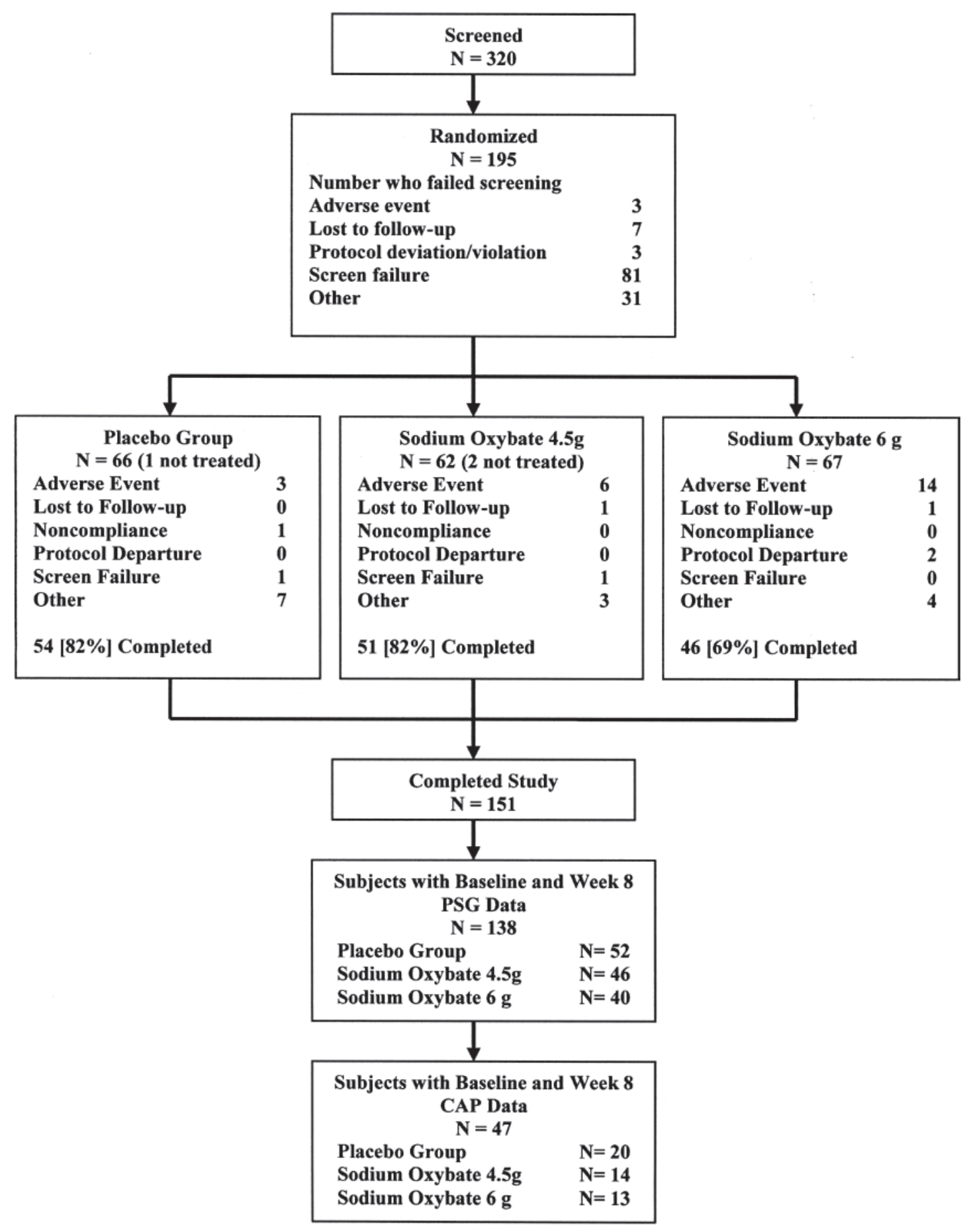

Figure 1. The progress of the study.

the study and indicated poor sleep quality (Tables 1 and 2) as well as high levels of pain, as reported by Russell, et $a l^{42}$. For the randomized population, the mean (SD) age was 46.5 (11.3) years, $94 \%$ were female, and the mean body mass index was 30.2 (7.5). A majority (74\%) had experienced FM symptoms for $>5$ years.
Subjective sleep, fatigue, and vitality at baseline. The self-reported sleep history at baseline was characterized by a high prevalence of sleep disturbances (Table 1), including short duration of sleep ( $\leq 6$ hours/night; reported by $74 \%$ ), awakening $\geq 3$ times/night (66\%), and light or very light sleep $(78 \%)$. 
Table 1. Baseline demographics and clinical characteristics. Non-missing data reported.

\begin{tabular}{|c|c|c|}
\hline Characteristic & $\begin{array}{l}\text { All Randomized } \\
\text { Patients }\end{array}$ & $\begin{array}{c}\text { Patients Who Completed } \\
\text { the Study }\end{array}$ \\
\hline No. patients & 195 & 151 \\
\hline Mean age, yrs (SD) & $46.5(11.3)$ & $46.9(11.0)$ \\
\hline Caucasian, \% & 92 & 91 \\
\hline Women, $\%$ & 94 & 94 \\
\hline Mean body mass index (SD) & $30.2(7.5)$ & $30.5(7.6)$ \\
\hline Duration of $\mathrm{FM} \geq 5 \mathrm{yrs}, \%$ & 74 & 76 \\
\hline \multicolumn{3}{|l|}{ Self-reported sleep } \\
\hline Sleep $\leq 6 \mathrm{~h} /$ night, $\%$ & 74 & 74 \\
\hline Awakening $\geq 3$ times/night, $\%$ & 66 & 68 \\
\hline Sleep depth = light or very light, $\%$ & 78 & 81 \\
\hline \multicolumn{3}{|l|}{ How refreshing is your sleep? } \\
\hline Mean (SD) & $77.0(19.9)$ & $77.0(19.6)$ \\
\hline Median (range) & $82.0(1.0-100.0)$ & $80.0(1.0-100.0)$ \\
\hline \multicolumn{3}{|l|}{ How sleepy do you usually feel in the morning? } \\
\hline Mean (SD) & $24.4(22.1)$ & $25.0(22.6)$ \\
\hline Median (range) & $17.0(0.0-100.0)$ & $19.0(0.0-100.0)$ \\
\hline \multicolumn{3}{|l|}{ How sleepy do you usually feel in the evening? } \\
\hline Mean (SD) & $31.9(28.8)$ & $31.9(29.5)$ \\
\hline Median (range) & $21.0(0.0-100.0)$ & $21.0(1.0-100.0)$ \\
\hline Mean PVAS, mm (SD) & $66.0(16.5)$ & $66.4(16.1)$ \\
\hline Median PVAS, mm (range) & $66.7(6.4-100.0)$ & $66.9(6.4-100.0)$ \\
\hline Daytime functioning, mean (SD) & $(\mathrm{n}=191)$ & $(\mathrm{n}=149)$ \\
\hline Functional outcome of sleep (range 5-20)* & $12.0(3.5)$ & $11.7(3.5)$ \\
\hline SF-36 Vitality domain (range $0-100$ )* & $28.7(6.0)$ & $29.0(6.0)$ \\
\hline \multicolumn{3}{|l|}{ Fibromyalgia Impact Questionnaire } \\
\hline How tired have you been? (range $0-10$ )** & $8.0(1.4)$ & $8.0(1.4)$ \\
\hline $\begin{array}{l}\text { How have you felt when you get up in the morning? } \\
\text { (range } 0-10)^{* *}\end{array}$ & $8.0(1.5)$ & $8.0(1.4)$ \\
\hline Sleep and daytime sleepiness, mean (SD) & $(\mathrm{n}=191)$ & $(\mathrm{n}=149)$ \\
\hline Jenkins Scale for Sleep (range 0-20) & $16.6(3.4)$ & $16.8(3.2)$ \\
\hline Epworth Sleepiness Scale (range 0-24)** & $11.2(5.7)$ & $11.9(5.6)$ \\
\hline Fatigue VAS (range $0-100)^{* *}$, mean $(\mathrm{SD})$ & $(\mathrm{n}=195)$ & $(\mathrm{n}=151)$ \\
\hline Overall & $69.7(16.2)$ & $70.2(15.7)$ \\
\hline Morning & $67.9(18.1)$ & $68.2(17.6)$ \\
\hline Afternoon & $68.3(16.8)$ & $68.9(16.5)$ \\
\hline Evening & $72.8(16.2)$ & $72.9(15.7)$ \\
\hline
\end{tabular}

* Lower scores indicate worse functioning. ** Higher scores indicate more tired, sleepy (Epworth Sleepiness Scale), or fatigued (Fatigue VAS) ${ }^{\dagger}$ Higher scores indicate worse sleep. VAS: visual analog scale; PVAS: pain visual analog scale.

Patients described their sleep as unrefreshing, with a mean VAS score (SD) for this question of 77.0 (19.9), suggesting poor sleep quality. Patients also reported high levels of morning and evening sleepiness, indicated by mean sleepiness VAS scores < 50, where lower numbers correspond to greater sleepiness. The mean ESS score (SD) was 11.2 (5.7), suggesting a predisposition to daytime sleepiness. Sleep disturbance was paralleled by a baseline JSS mean score (SD) of 16.6 (3.4), a FOSQ mean score of 12.0 (3.5), and an SF-36 Vitality domain mean score of 28.7 (6.0). High levels of fatigue were reported, with mean baseline FVAS scores of 69.7 (16.2) on a 0-100 scale where higher scores indicate worse fatigue.

Polysomnography. Baseline PSG data were available for 181 of the randomized patients meeting ACR criteria for
FM, with CAP data analyzed in 88 patients (Table 2). The sleep architecture was consistent with the self-reported sleep history in showing delayed onset to sleep and impaired sleep efficiency. A total CAP rate of $62.7 \%$ was recorded in these patients.

Efficacy analysis. Of 320 patients screened, 195 were randomized and 192 were treated. Adverse events led to early study termination in $3(4.5 \%), 6(9.7 \%)$, and $14(20.9 \%)$ patients from the placebo, SXB $4.5 \mathrm{~g} / \mathrm{night}$, and SXB 6 $\mathrm{g} /$ night groups, respectively. Reasons for termination from the study were summarized according to prespecified categories.

Efficacy. Subjective sleep and daytime fatigue and vitality. As shown in Figure 2, SXB resulted in a dose-dependent decrease in daytime fatigue measured by FVAS, with signif-

Personal non-commercial use only. The Journal of Rheumatology Copyright @ ( 2010. All rights reserved. 
Table 2. Baseline objective polysomnographic (PSG) data. All results reported as mean (SD). Non-missing data reported.

\begin{tabular}{lcc}
\hline Polysomnographic Data & $\begin{array}{c}\text { All Randomized } \\
\text { Patients }\end{array}$ & $\begin{array}{c}\text { Patients Who Completed } \\
\text { the Study }\end{array}$ \\
\hline No. patients & 195 & 151 \\
Objective sleep/wake outcome measures & $(\mathrm{n}=181)$ & $(\mathrm{n}=138)$ \\
Total sleep time, min & $362.9(74.9)$ & $367.2(72.6)$ \\
Sleep onset latency, min & $26.0(27.0)$ & $24.7(26.8)$ \\
Wake after sleep onset, min & $73.8(55.2)$ & $75.5(53.4)$ \\
No. awakenings & $25.5(11.6)$ & $25.8(11.6)$ \\
Sleep efficiency, $\%$ & $76.5(15.5)$ & $77.2(15.0)$ \\
Duration of sleep stages assessed by PSG & $(\mathrm{n}=180)$ & $(\mathrm{n}=136)$ \\
Rapid eye movement (REM), min & $76.1(32.9)$ & $77.5(33.8)$ \\
Non-REM, min & $286.9(59.7)$ & $289.6(58.6)$ \\
Stage 1, min & $41.2(21.5)$ & $42.1(22.7)$ \\
Stage 2, min & $203.1(55.9)$ & $206.4(56.0)$ \\
Slow-wave sleep, min & $42.5(34.7)$ & $41.1(30.4)$ \\
Rate of cyclic alternating pattern (CAP) & $(\mathrm{n}=88)$ & $(\mathrm{n}=47)$ \\
Total CAP rate & $62.7(21.7)$ & $65.3(17.5)$ \\
Phase A1 CAP rate, $\%$ & $48.4(20.0)$ & $52.4(16.7)$ \\
Phase A2/A3 CAP rate, \% & $14.3(7.7)$ & $12.9(5.3)$ \\
\hline
\end{tabular}

\section{Overall}

(Baseline 70.2 \pm 15.7 )
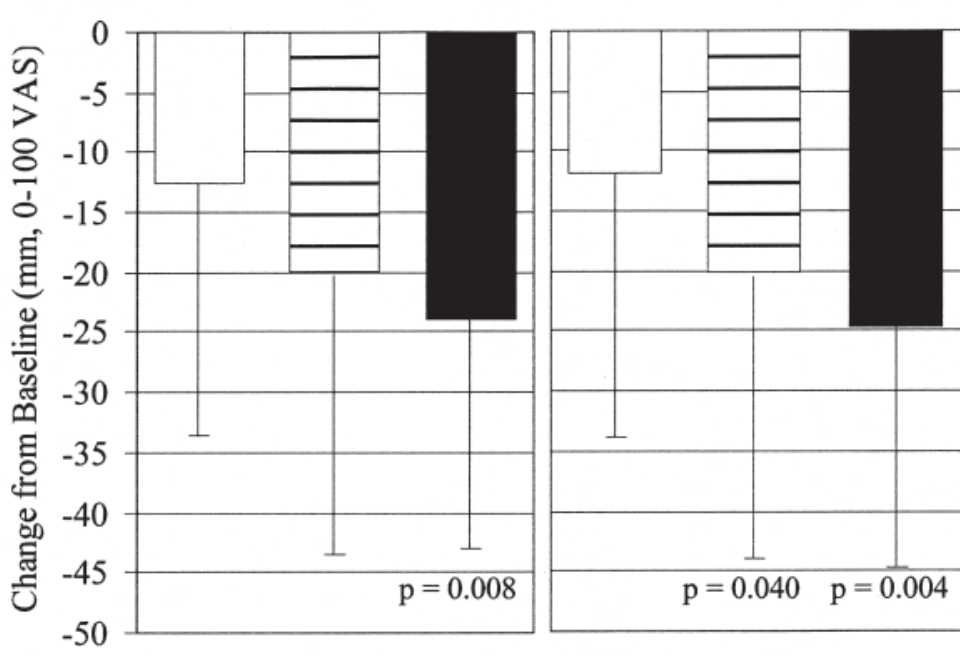

Afternoon

(Baseline 68.9 \pm 16.5 )
Evening

(Baseline $72.9 \pm 15.7$ )
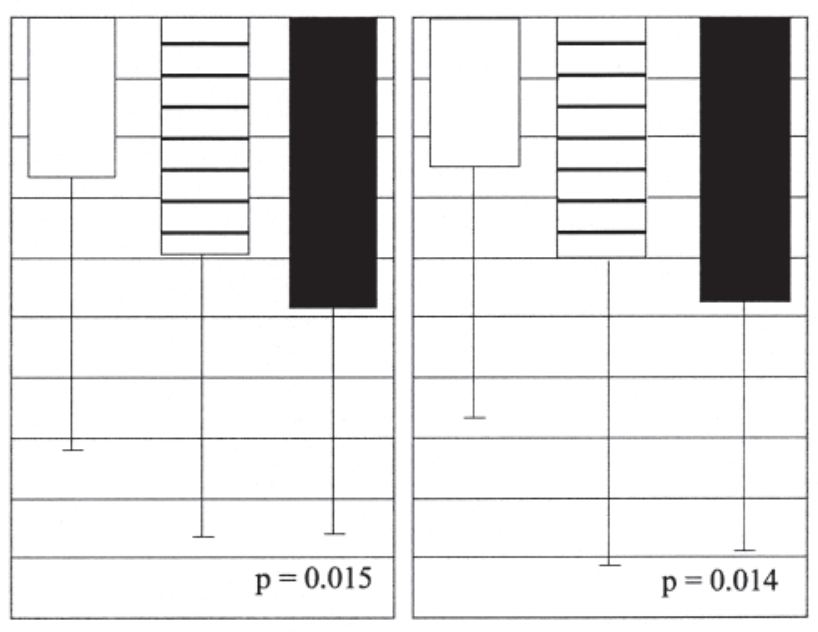

\section{$\square$ Placebo}

Sodium Oxybate $4.5 \mathrm{~g}$

Sodium Oxybate $6 \mathrm{~g}$

Figure 2. Mean $( \pm \mathrm{SD})$ change from baseline in daytime fatigue visual analog scale (VAS) in patients who completed the study. P values indicate pairwise comparison of given SXB dose and placebo.

icant reductions compared with placebo noted for morning, afternoon, evening, and overall with SXB $6 \mathrm{~g}$ and for morning only with SXB $4.5 \mathrm{~g}$.

As shown in Figure 3, both SXB $4.5 \mathrm{~g}$ and SXB $6 \mathrm{~g}$ significantly improved JSS and ESS. Dose-dependent reductions with SXB $4.5 \mathrm{~g}$ and SXB $6 \mathrm{~g}$ versus placebo were noted for both JSS and ESS. On the JSS, there were statisti- cally significantly greater improvements with SXB $4.5 \mathrm{~g}$ and SXB $6 \mathrm{~g}$, of $-7.1 \pm 5.9(\mathrm{p}=0.002)$ and $-8.4 \pm 5.1(\mathrm{p}<$ $0.001)$, respectively, than with placebo $(-3.8 \pm 5.2)$. On the ESS, there were statistically significantly greater improvements with SXB $4.5 \mathrm{~g}$ and SXB $6 \mathrm{~g},-3.1 \pm 4.8(\mathrm{p}=0.039)$ and $-4.7 \pm 5.1(\mathrm{p}<0.001)$, respectively, than with placebo $(-1.0 \pm 5.2)$. 

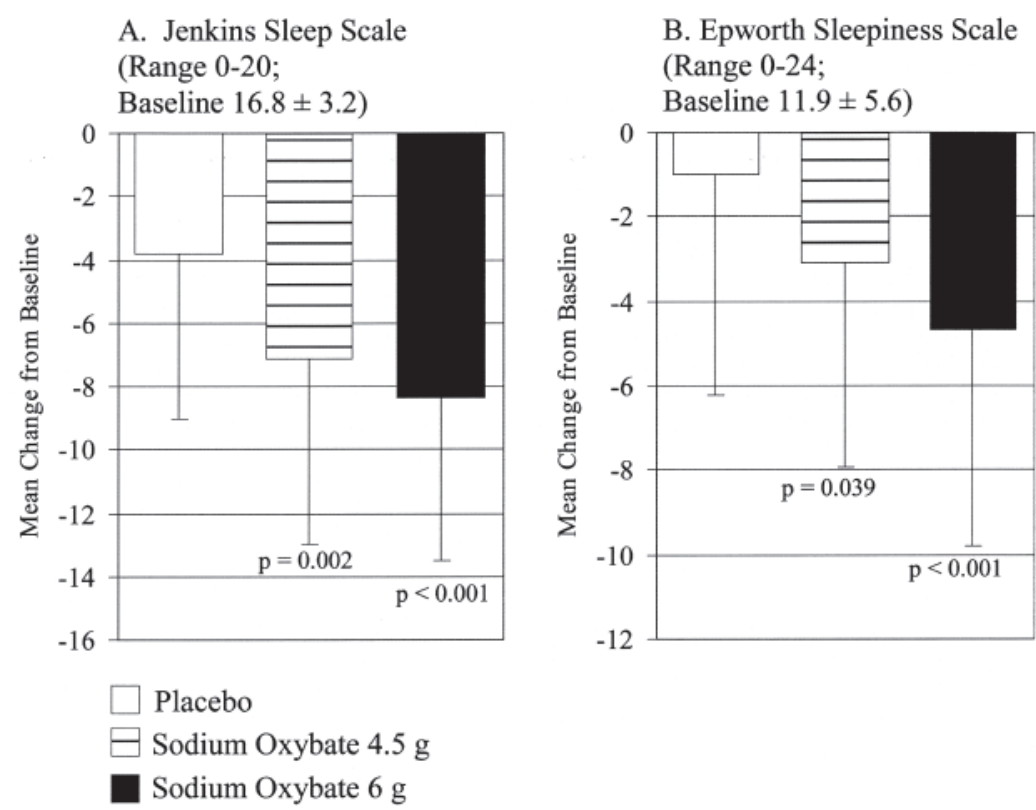

Figure 3. Mean $( \pm \mathrm{SD})$ change from baseline on 2 subjective sleep questionnaires in patients who completed the study. P values indicate pairwise comparison of given SXB dose and placebo.

Subjective indicators of daytime functioning. As shown in Table 3, concomitant with improvements in objective sleep and subjective fatigue outcomes, patients treated with SXB reported improvements on measures of daytime functioning that were significantly superior to placebo. Significant improvements at both doses of SXB were seen on the FOSQ, the SF-36 Vitality domain, and the FIQ questions "How tired have you been?" and "How have you felt when you get up in the morning?".

Polysomnography. PSG data were available in 138 of 151 completed patients, with CAP data analyzed in 47 patients. As shown in Table 4, compared to placebo, SXB 6 g significantly increased non-REM stage 2 sleep, SWS, and total non-REM sleep. Both SXB $4.5 \mathrm{~g}$ and SXB $6 \mathrm{~g}$ significantly reduced REM sleep time compared with placebo. The change from baseline in total sleep time and sleep efficiency was increased with SXB 6 g compared with placebo with near-statistical significance. A statistically significant reduction in WASO was noted for SXB $6 \mathrm{~g}$, and an increase was noted with near-statistical significance for SXB $4.5 \mathrm{~g}$. The phase A1 CAP rate showed an increase for both doses of SXB versus placebo; however, this increase was not statistically significant. For the phase A2/A3 CAP rate, both SXB doses showed a greater decrease than placebo and this change was statistically significant for the SXB 6 g group.

Correlations. Weak correlations (absolute value $\leq 0.38$ ) were seen between most measures of change in PSG and measures of change in subjective sleep. However, for the SXB $6 \mathrm{~g}$ group, moderate correlations ( 0.56 to 0.61$)$ were demonstrated between reduction in the phase A1 CAP rate and reduc-

Table 3. Change from baseline in subjective clinical characteristics at Week 8 (patients who completed the study). All data reported as mean (SD).

\begin{tabular}{|c|c|c|c|c|c|}
\hline & Placebo & $\begin{array}{c}\text { Sodium } \\
\text { Oxybate } \\
4.5 \mathrm{~g}\end{array}$ & $\begin{array}{l}\mathrm{p} v \mathrm{vs} \\
\text { Placebo }\end{array}$ & $\begin{array}{c}\text { Sodium } \\
\text { Oxybate } \\
6 \mathrm{~g}\end{array}$ & $\begin{array}{l}\mathrm{p} \text { vs } \\
\text { Placebo }\end{array}$ \\
\hline No. patients & 54 & 51 & & 46 & \\
\hline \multicolumn{6}{|c|}{ Subjective indicators of daytime functioning } \\
\hline Functional outcome of sleep $(5-20)^{*}$ & $1.0(3.3)$ & $2.6(3.6)$ & 0.027 & $2.7(4.0)$ & 0.028 \\
\hline SF-36 Vitality domain $(0-100)^{*}$ & $5.5(10.0)$ & $11.1(12.8)$ & 0.016 & $12.8(12.1)$ & 0.003 \\
\hline \multicolumn{6}{|l|}{ Fibromyalgia Impact Questionnaire } \\
\hline How tired have you been? $(0-10)^{* *}$ & $-1.3(2.4)$ & $-2.7(2.9)$ & 0.009 & $-3.1(2.5)$ & 0.001 \\
\hline $\begin{array}{l}\text { How have you felt when you get up } \\
\text { in the morning? }(0-10)^{* *}\end{array}$ & $-1.7(2.2)$ & $-3.0(3.0)$ & 0.009 & $-3.3(2.5)$ & 0.002 \\
\hline
\end{tabular}

* Increase indicates improvement. ** Decrease indicates improvement. 
Table 4. Change from baseline in objective polysomnographic measures at Week 8 (patients who completed the study). All data reported as mean (SD).

\begin{tabular}{|c|c|c|c|c|c|}
\hline & Placebo S & $\begin{array}{c}\text { Sodium Oxybate } \\
4.5 \mathrm{~g}\end{array}$ & $\begin{array}{c}\text { p vs } \\
\text { Placebo }\end{array}$ & $\begin{array}{c}\text { Sodium Oxybate } \\
6 \mathrm{~g}\end{array}$ & $\begin{array}{c}\mathrm{p} \text { vs } \\
\text { Placebo }\end{array}$ \\
\hline No. patients & 54 & 51 & & 46 & \\
\hline Sleep/wake measures & $(\mathrm{n}=52)$ & $(n=46)$ & & $(n=40)$ & \\
\hline Total sleep time, $\min$ & $10.1(76.0)$ & $-11.4(52.3)$ & 0.134 & $39.4(79.1)$ & 0.050 \\
\hline Sleep onset latency, min & $0.9(46.9)$ & $3.2(23.0)$ & 0.760 & $-5.9(36.9)$ & 0.394 \\
\hline Wake after sleep onset, min & $-16.2(46.3)$ & $4.2(46.3)$ & 0.053 & $-39.7(62.0)$ & 0.032 \\
\hline No. awakenings & $-4.3(12.9)$ & $-5.4(8.5)$ & 0.660 & $-7.1(12.5)$ & 0.268 \\
\hline Sleep efficiency, $\%$ & $3.0(16.0)$ & $-2.4(11.1)$ & 0.068 & $8.9(15.3)$ & 0.052 \\
\hline Sleep stages & $(\mathrm{n}=52)$ & $(n=45)$ & & $(n=39)$ & \\
\hline Rapid eye movement (REM), min & $-2.3(32.6)$ & $-23.8(32.2)$ & 0.003 & $-18.6(39.0)$ & 0.027 \\
\hline Non-REM, min & $12.4(61.2)$ & $12.4(56.0)$ & 0.996 & $57.9(70.9)$ & $<0.001$ \\
\hline Stage $1, \min$ & $-4.0(23.6)$ & $-6.1(21.5)$ & 0.673 & $-8.9(28.7)$ & 0.345 \\
\hline Stage $2, \min$ & $18.1(60.5)$ & $4.9(59.8)$ & 0.309 & $47.5(70.5)$ & 0.030 \\
\hline Slow-wave sleep, min & $-1.7(34.0)$ & $13.6(49.2)$ & 0.091 & $19.4(49.8)$ & 0.026 \\
\hline Rate of cyclic alternating pattern (C) & $(n=20)$ & $(n=14)$ & & $(n=13)$ & \\
\hline Phase A1 CAP rate, $\%$ & $-0.1(11.2)$ & $5.8(9.2)$ & 0.172 & $7.0(16.2)$ & 0.108 \\
\hline Phase A2/A3 CAP rate, $\%$ & $-0.4(3.5)$ & $-2.1(3.2)$ & 0.180 & $-3.9(3.7)$ & 0.007 \\
\hline
\end{tabular}

tions in the JSS total score, the JSS item on trouble falling asleep, and the JSS item regarding waking up after usual amount of sleep feeling tired and worn out $(n=13)$.

Moderate correlations (absolute value $\geq 0.40$ ) were demonstrated between several measures of improvement in subjective sleep (JSS total, JSS items, and the ESS total) and reductions in pain using several measures (PVAS, FIQ Pain, and the SF-36 Bodily Pain domain). For each treatment group and overall, the strongest correlations were seen between reduction in the Jenkins item regarding waking up after usual amount of sleep feeling tired and worn out and improvement on 2 pain items: FIQ Pain $(\geq 0.58)$ and SF-36 Bodily Pain $(\leq-0.53)$.

Tolerability and safety. Safety data for all treated patients are shown in Table 5, as reported ${ }^{42}$. Treatment-emergent adverse events were reported in the majority of patients receiving placebo, SXB $4.5 \mathrm{~g}$, and SXB $6 \mathrm{~g}(60.0 \%, 68.3 \%$, and $77.6 \%$, respectively). The difference in these proportions was not statistically significant $(\mathrm{p}=0.09)$. Two patients experienced serious adverse events: one patient experienced respiratory tract infection and exacerbation of asthma; a second patient experienced tachycardia, hypertension, and bipolar disorder. Although none were considered related to study drug or procedures by the investigators, the sponsor could not rule out a relationship to study drug for the bipolar disorder. Adverse events occurring at $>2 \%$ and differing significantly between active and placebo groups included nausea, pain in extremity, nervous system disorders, dizziness, restlessness, renal and urinary disorders, and urinary incontinence. Most of the observed adverse events were mild or moderate in severity. No clinically important changes in vital signs, laboratory measures, general examination findings, neurological examination findings, or electrocardiograms were observed.

\section{DISCUSSION}

This is the first study in a large cohort of patients with FM syndrome to assess objective and subjective measures of disrupted sleep. Compared with historical measures in healthy subjects of similar age ${ }^{43}$, there was a high prevalence of disrupted non-REM sleep and alpha EEG sleep disorder ${ }^{14}$, and periodic sleep disturbances as shown by elevated CAP frequency, sleep-disordered breathing, and sleep-related periodic limb movements of sleep in subjects who were evaluated by PSG. The total CAP rate of $62.7 \%$ in these patients was substantially higher than in the $41 \%$ to $45 \%$ reported for normal subjects ${ }^{18}$, suggesting the occurrence of greater spontaneous arousability, poorer sleep quality, and greater sleep instability and fragmentation in patients with FM.

Moderate to severe sleep-disordered breathing (obstructive Apnea-Hypopnea Index $\geq 15$ /hour) was noted in $15.3 \%$ of screened subjects with FM, mostly women, compared with a lower prevalence reported in the general US population. The prevalence of moderate to severe sleep-disordered breathing has been estimated as $4.0 \%$ for women and $9.1 \%$ for men ages $30-60$ years in a large $(n=609)$ US study using PSG $^{44}$. Patients with clinically significant obstructive sleep apnea disorder and periodic leg movements with arousals/restless legs syndrome were excluded from participation in the treatment portion of this study; thus investigations of the effects of treatment on these co-occurring primary sleep disorders in FM merit consideration. Recently, the effects of SXB in patients with mild to moderate sleep apnea syndrome were reported ${ }^{45,46}$; caution is noted about the use of SXB in patients with compromised respiratory function ${ }^{47}$.

There are several limitations to our study. The sleep physiology data are descriptive, with comparisons made to

Personal non-commercial use only. The Journal of Rheumatology Copyright (C) 2010. All rights reserved. 
Table 5. Adverse events affecting $\geq 2 \%$ of the patients and that differed significantly in frequency between sodium oxybate and placebo (all treated patients). All data reported as number (\%) of patients.

\begin{tabular}{lcccc}
\hline & \multicolumn{4}{c}{ Sodium Oxybate } \\
& Placebo & $4.5 \mathrm{~g}$ & $6 \mathrm{~g}$ & $\mathrm{p}$ vs Placebo \\
\hline No. patients & 65 & 60 & 67 & \\
Adverse event & & & & \\
$\quad$ Nausea & $6(9.23)$ & $10(16.67)$ & $19(28.36)$ & 0.02 \\
Pain in extremity & $0(0)$ & $4(6.67)$ & $0(0)$ & 0.009 \\
Nervous system disorders* & $9(13.85)$ & $16(26.67)$ & $27(40.3)$ & 0.003 \\
Dizziness & $2(3.08)$ & $5(8.33)$ & $12(17.91)$ & 0.01 \\
Restlessness & $0(0)$ & $3(5)$ & $0(0)$ & 0.03 \\
Renal and urinary disorders & $0(0)$ & $1(1.67)$ & $5(7.46)$ & 0.04 \\
Urinary incontinence & $0(0)$ & $0(0)$ & $4(6.0)$ & 0.004 \\
\hline
\end{tabular}

* Includes dizziness, headache, paresthesia, and somnolence. P values determined by Fisher's exact test (2 degrees of freedom).

published data of a similar age-matched population. Comparisons were not possible with age-matched controls from the various participating sleep laboratories. The relatively high incidence of sleep-disordered breathing in the screened FM population may have been due in part to the adverse effects of opioids and sedative hypnotics, medications known to be respiratory depressants. No adjustment for multiplicity was made in the analysis of the study's secondary endpoints, which are the subject of this report. Although statistically significant improvements in pain were noted previously with both SXB $4.5 \mathrm{~g}$ and SXB $6 \mathrm{~g}^{42}$, the majority of the modifications in sleep architecture occurred at the higher dose of SXB. In fact, SXB $4.5 \mathrm{~g}$ had minimal effects on conventional sleep stage measures, and thus no association between the effects of SXB on sleep architecture at low dose and the demonstrated efficacy in pain reduction $^{41}$ was evident. Indeed, there seemed to be a trend to an increase in WASO with a decline in sleep efficiency. Although CAP analysis has been proposed as a more sensitive measure of sleep disruption in $\mathrm{FM}^{18}$, it was available only in a subset of the patients in this study. Thus it is unclear if these results are representative of the entire sample. Finally, the neurophysiological mechanisms by which SXB benefits the constellation of unrefreshing sleep, widespread pain, and fatigue symptoms in patients with FM remain to be determined.

This study showed that in addition to improving pain, the hallmark symptom of $\mathrm{FM}^{42}$, SXB 6 g modified objective PSG measures of sleep, not only by increasing the duration of non-REM sleep time and increasing the duration of SWS, but also by reducing the duration of time in REM sleep (at both doses). Such changes in sleep physiology are paralleled by improvements in subjective sleep disturbance (JSS) and morning fatigue (FVAS). With SXB $6 \mathrm{~g}$, there was also improvement in afternoon, evening, and overall fatigue. In addition, there was significant subjective improvement in the SF-36 Vitality subscale, a measure of function; the FIQ self-ratings of general and morning tiredness; daytime sleepiness measured by the ESS; and the functional effects of daytime somnolence as measured by the FOSQ.

Moderate correlations were observed across multiple measures of subjective sleep and pain, supporting a relationship between these 2 domains. However, since the moderate correlations seen for the SXB $6 \mathrm{~g}$ group between phase A1 CAP rate and JSS total, and 2 JSS items were based on few subjects $(n=13)$, further research is warranted to investigate these relationships.

This research confirms the results of the preliminary study by Scharf, et al demonstrating the benefits of SXB in improving sleep and symptoms of $\mathrm{FM}^{33}$. SXB facilitates slow-wave sleep and reduces the wakefulness after sleep onset while reducing physiological sleep instability, perception of pain, and fatigue. SXB is the first drug to demonstrate, under controlled conditions, the benefit of the key features of FM syndrome, which include the constellation of symptoms that comprise nonrestorative sleep, chronic fatigue, and widespread pain. Whether the sleep and fatigue improvements occur independently of the effects of SXB on pain and functionality remains to be determined.

\section{ACKNOWLEDGMENT}

The Oxybate SXB-26 FM-Study Group multicenter participants included the following, listed alphabetically: Adam Barron, MD, Radiant Research, West Palm Beach, FL; Robert M. Bennett, MD, FRCP, Oregon Health Science University, Rheumatology, Portland, OR; Isam Diab, MD, Middleburg Heights, OH; Joseph S. Habros, MD, Radiant Research, Scottsdale, AZ; Andrew J. Holman, MD, Pacific Rheumatology Associates, Inc., Renton, WA; Alan Kivitz, MD, Altoona Center for Clinical Research, Duncansville, PA; Elliot Kopp, MD, Raleigh Neurology, Raleigh, NC; Philip Mease, MD, Seattle Rheumatology Associates, Swedish Rheumatology Research, Seattle, WA; Abigail Neiman, MD, Katy, TX; David Nordstrom, MD, Lynn Institute of the Rockies, Colorado Springs, CO; John Pappas, MD, Central Kentucky Research Associates, Lexington, KY; Ashwin Patkar, MD, Duke University Medical Center, Durham, NC; I. Jon Russell, MD, PhD, University Clinical Research Center, University of Texas Health Science Center at San Antonio, San Antonio, TX; David Seiden, MD, Broward Research Group, Pembrooke Pines, FL; Eric A. Sheldon, MD, Miami Research Associates, Miami, FL; Stuart L. Silverman, MD, OMC Research Center, Beverly Hills, CA; N. Lee Smith, 
MD, Stress Medicine Clinic, Health South Rehab Hospital, Sandy, UT; Daniel Wallace, MD, Wallace Rheumatic Study Center, Los Angeles, CA; Larry G. Willis, MD, Lynn Health Science Institute, Oklahoma City, OK; John B. Winfield, MD, Alvin Daughtridge Arthritis Center, Lenoir, NC; and Patrick Wood MD, Psychopharmacology Research Clinic, Louisiana State University Health Sciences Center School of Medicine, Shreveport, LA.

In compliance with Good Publication Practice For Pharmaceutical Companies (www.gpp-guidelines.org), the authors acknowledge the developmental work and research leadership of William Houghton, MD, and Harry Cook, RPh, MBA.

\section{REFERENCES}

1. Wolfe F, Smythe HA, Yunus MB, Bennett RM, Bombardier C, Goldenberg DL, et al. The American College of Rheumatology 1990 criteria for the classification of fibromyalgia: report of the multicenter criteria committee. Arthritis Rheum 1990;33:160-72.

2. Bennett RM, Jones J, Turk DC, Russell IJ, Matallana L. An internet survey of 2,596 people with fibromyalgia. BMC Musculoskel Disord 2007;8:27.

3. Hauser W, Zimmer C, Felde E, Kollner V. [What are the key symptoms of fibromyalgia? Results of a survey of the German Fibromyalgia Association.] Schmerz 2008;22:176-83.

4. Bigatti SM, Hernandez AM, Cronan TA, Rand KL. Sleep disturbances in fibromyalgia syndrome: Relationship to pain and depression. Arthritis Care Res 2008;59:951-67.

5. Mease P, Arnold LM, Choy EH, Clauw DJ, Crofford LJ, Glass JM, et al; OMERACT Fibromyalgia Working Group. Fibromyalgia syndrome module at OMERACT 9: Domain construct. J Rheumatol 2009;36:2318-29.

6. Affleck G, Urrows S, Tennen H, Higgins P, Abeles M. Sequential daily relations of sleep, pain intensity, and attention to pain among women with fibromyalgia. Pain 1996;68:363-8.

7. Hamilton NA, Affleck G, Tennen H, Karlson C, Luxton D, Preacher KJ, et al. Fibromyalgia: The role of sleep in affect and in negative event reactivity and recovery. Health Psychol 2008;27:490-7.

8. Moldofsky H, Scarisbrick P, England R, Smythe H. Musculoskeletal symptoms and NREM sleep disturbances in patients with "fibrositis" syndrome and healthy subjects. Psychosom Med 1975;37:341-51.

9. Moldofsky H. The significance of the sleeping-waking brain for the understanding of widespread musculoskeletal pain and fatigue in fibromyalgia syndrome and allied syndromes. J Joint Bone Spine 2008;75:397-402.

10. Branco J, Atalaia A, Paiva T. Sleep cycles and alpha-delta sleep in fibromyalgia syndrome. J Rheumatol 1994;21:1113-7.

11. Drewes AM, Gade J, Nielsen KD, Bjerregård K, Taagholt SJ, Svendsen L. Clustering of sleep encephalographic patterns in patients with the fibromyalgia syndrome. Br J Rheumatol 1995;34:1151-6.

12. Roizenblatt S, Moldofsky H, Benedito AA, Tufik S. Alpha sleep characteristics in fibromyalgia. Arthritis Rheum 2001;44:222-30.

13. Roizenblatt S, Tufik S, Goldenberg J, Pinto LR, Hilario MO, Feldman D. Juvenile fibromyalgia. Clinical and polysomnographic aspects. J Rheumatol 1997;24:579-85.

14. Anch A, Lue F, McLean A, Moldofsky H. Sleep physiology and psychological aspects of fibrositis syndrome. Can J Psychol 1991;45:179-84.

15. Chervin RD, Teodorescu M, Kushwaha R, Andrea M, Deline AM, Brucksch CB, et al. Objective measures of disordered sleep in fibromyalgia. J Rheumatol 2009;36:2009-16.

16. Landis CA, Lentz MJ, Rothermel J, Buchwald D, Shaver JL. Decreased sleep spindles and spindle activity in midlife women with fibromyalgia and pain. Sleep 2004;27:741-50.

17. Burns JW, Crofford LJ, Chervin RD. Sleep stage dynamics in fibromyalgia patients and controls. Sleep Med 2008;9:689-96.
18. Rizzi M, Sarzi-Puttini P, Atzeni F, Capsoni F, Andreoli A, Pecis M, et al. Cyclical alternating pattern: A new marker for sleep alteration in patients with fibromyalgia. J Rheumatol 2004;34:1193-9.

19. Hicks RA, Coleman DD, Ferrante F, Sahatjian M, Hawkins J. Pain thresholds in rats during recovery from REM sleep deprivation. Percept Mot Skills 1979;48:687-90.

20. Hakki Onen S, Alloui A, Jourdan D, Eschalier A, Dubray C. Effects of rapid eye movement (REM) sleep deprivation on pain sensitivity in the rat. Brain Res 2001;900:261-7.

21. Moldofsky H, Scarisbrick P. Induction of neurasthenic musculoskeletal pain syndrome by selective sleep stage deprivation. Psychosom Med 1976;38:35-44.

22. Older SA, Battafarano DF, Danning CL, Ward JA, Grady EP, Derman S, et al. The effects of delta wave sleep interruption on pain thresholds and fibromyalgia-like symptoms in healthy subjects; correlations with insulin-like growth factor. Int J Rheumatol 1998;25:1180-6.

23. Lentz MJ, Landis CA, Rothermel J, Shaver JL. Effects of selective slow wave sleep disruption on musculoskeletal pain and fatigue in middle aged women. J Rheumatol 1999;26:1586-92.

24. Onen SH, Alloui A, Gross A, Eschallier A, Dubray C. The effects of total sleep deprivation, selective sleep interruption and sleep recovery on pain tolerance thresholds in healthy subjects. Sleep Res 2001;10:35-42.

25. Kundermann B, Spernal J, Huber MT, Krieg JC, Lautenbacher S. Sleep deprivation affects thermal pain thresholds but not somatosensory thresholds in healthy volunteers. Psychosom Med 2004;66:932-7.

26. Roehrs T, Hyde M, Blaisdell B, Greenwald M, Roth T. Sleep loss and REM sleep loss are hyperalgesic. Sleep 2006;29:145-51.

27. Smith MT, Edwards RR, McCann UD, Haythornthwaite JA. The effects of sleep deprivation on pain inhibition and spontaneous pain in women. Sleep 2007;30:494-505.

28. Reynolds WJ, Moldofsky H, Saskin P, Lue FA. The effects of cyclobenzaprine on sleep physiology and symptoms in patients with fibromyalgia. J Rheumatol 1991;18:452-4.

29. Carette S, Oakson G, Guimont C, Steriade M. Sleep electroencephalography and the clinical response to amitriptyline in patients with fibromyalgia. Arthritis Rheum 1995;38:1211-7.

30. Drewes AM, Andreasen A, Jennum P, Nielsen KD. Zopiclone in the treatment of sleep abnormalities in fibromyalgia. Scand J Rheumatol 1991;20:288-93.

31. Moldofsky H, Lue FA, Mously C, Roth-Schechter B, Reynolds WJ. The effect of zolpidem in patients with fibromyalgia: a dose ranging, double blind, placebo controlled, modified crossover study. J Rheumatol 1996;23:529-33.

32. Mamelak M, Black J, Montplaisir J, Ristanovic R. A pilot study on the effects of sodium oxybate on sleep architecture and daytime alertness in narcolepsy. Sleep 2004;27:1327-34.

33. Scharf MB, Baumann M, Berkowitz DV. The effect of sodium oxybate on clinical symptoms and sleep patterns in patients with fibromyalgia. J Rheumatol 2003;30:1070-4.

34. Jenkins CD, Stanton BA, Niemcryk SJ, Rose RM. A scale for the estimation of sleep problems in clinical research. J Clin Epidemiol 1988:41:313-21.

35. Johns MW. A new method for measuring daytime sleepiness: the Epworth Sleepiness Scale. Sleep 1991;14:540-5.

36. Weaver TE, Laizner AM, Evans LK, Maislin G, Chugh DK, Lyon $\mathrm{K}$, et al. An instrument to measure functional status outcomes for disorders of excessive sleepiness. Sleep 1997;20:835-43.

37. Ware JE, Snow KK, Kosinski M, Gandek B. SF-36 Health Survey: Manual and interpretation guide. Lincoln, RI: QualityMetric Inc.; 2000.

38. Burckhardt CS, Clark SR, Bennett RM. The Fibromyalgia Impact Questionnaire: development and validation. J Rheumatol 
1991;18:728-33.

39. Rechtschaffen A, Kales A, editors. A manual of standardized terminology, techniques and scoring system for sleep stages of human subject. Washington, DC: US Government Printing Office, National Institute of Health Publication; 1968.

40. Rosa AC, Parrino L, Terzano MG. Automatic detection of cyclic alternating pattern (CAP) sequences in sleep: preliminary results. Clin Neurophysiol 1999;110:585-92.

41. Rosa A, Alves GR, Brito M, Lopes MC, Tufik S. Visual and automatic cyclic alternating pattern (CAP) scoring: inter-rater reliability study. Arq Neuropsiquiatr 2006;64:578-81.

42. Russell IJ, Bennett RM, Michalek JE. Oxybate for FMS Study Group. Sodium oxybate relieves pain and improves function in fibromyalgia syndrome: A randomized, double-blind, placebo-controlled, multicenter clinical trial. Arthritis Rheum 2009:60:299-309.
43. Hume KI, Van F, Watson A. A field study of age and gender differences in habitual adult sleep. J Sleep Res 1998;7:85-94.

44. Young T, Palta M, Dempsey J, Skatrud J, Weber S, Badr S. The occurrence of sleep-disordered breathing among middle-aged adults. New Engl J Med 1993;328:1230-5.

45. George CFP, Feldman N, Zheng Y, Steininger TL, Grzeschik SM, Lai C, et al. A 2-week, polysomnographic, safety study of sodium oxybate in obstructive sleep apnea syndrome. Sleep Breath 2010 Jan 18; Epub ahead of print.

46. George CFP, Feldman N, Inhaber NH, Steininger TL, Grzeschik SM, Lai C, et al. A safety trial of sodium oxybate in patients with obstructive sleep apnea: acute effects on sleep-disordered breathing. Sleep Med 2010;11:38-42.

47. Feldman NT. Xyrem safety: the debate continues. Sleep Med 2009;10:405-6. 